\title{
Effects of Different Combination of Growing Media on Growth and Total Phenolic Content in Labisia pumila (Kacip Fatimah)
}

\author{
M.A. Farah Fazwa*, S. Norhayati, S.N. Syafiqah Nabilah, S.R. Keeren \\ Plant Improvement Programme, Forestry Biotechnology Division, Forest Research Institute Malaysia (FRIM), 52109, Kepong, Selangor, Malaysia.
}

\section{ARTICLE DETAILS}

\section{Article history:}

Received 02 September 2020

Accepted 18 September 2020

Available online 05 October 2020

\section{Keywords:}

Kacip Fatimah

Phenolic Compounds

Compost

Soil Media

\begin{abstract}
A B S T R A C T
Labisia pumila, locally known in Malaysia as Kacip Fatimah, is highly-prized for its phenols. Phenolic compounds in L. pumila has numerous pharmacological properties such as having anti-oxidant, antimicrobial, anti-inflammatory and anti-cancer potential. The production of phenolic contents in plants is influence by various factor, including abiotic factors such as soil properties. Thus, the objective of this study was to determine the effects of different combinations of growing media on the growth and total phenolic content in L. pumila leaves. Six combinations of growing media were used, each using different types of compost that had differing amounts of L. pumila leaves. The plants were grown in all media for a period of six months at FRIM's nursery. Besides growth performance, the total phenolic content was also determined, six months after planting. There was no significant difference in growth parameters for all treatments, with the exception of control (significantly lower than all treatments). However, the total phenolic content of Treatment 1 (80.6 mg GAE/g) was significantly higher than all other treatments. This can be attributed to the properties of Compost 1 (which was in the growth media of Treatment 1), as it had the highest $\mathrm{pH}(5.26)$, the highest potassium concentration $(0.7 \%)$ and high nitrogen concentrations $(1.32 \%)$. The composition of Compost 1 was 5 kg dry leaves + 500 g dry Kacip Fatimah + Slow Release Fertilizer (SRF). Results from this study showed that growing media is a key factor that leads to significant increment in phenolic compounds in L. pumila.
\end{abstract}

\section{Introduction}

Despite only having $0.2 \%$ of the world's land mass, Malaysia is one of the most biodiverse countries in the world, ranking $12^{\text {th }}$ in the National Biodiversity Index [1]. This biodiversity is the foundation for the nation's economy, contributing in terms of ecotourism, timber products, food security and medicinal herbs. Medicinal herbs have long been used in Malaysian traditional medicine. Nowadays, it's commonly used as health supplements, cosmetics and in alternative medicine [2]. The global demand for medicinal herbs is ever increasing, fueled by the rapid growth of the world's herbal industry. According to the World Health Organization (WHO), it is estimated about $80 \%$ of the world's population use herbal medicine [3]. The highest global market share for herbal products is western herbalism (45.9\%), followed by traditional Chinese medicine (36.6\%), homeopathy (9.7\%) and Ayurveda (7.8\%) [4]. Thus, it is apparent that the global herbal industry is dominated by the Western world and China.

However, Malaysia is slowly becoming a key player in world's herbal industry. Even in the 1930s, I.H. Burkill (the director of the Singapore Botanic Gardens) had said that Malaysia has the potential to supply the world's medicinal herbs, documenting approximately 2000 Malaysian herbs that had medicinal qualities [5]. In 2000, the estimated market for Malaysian herbal medicine was about RM2.28 billion, and is expected to reach RM32 billion in 2020 [4]. Although the COVID-19 pandemic has slowed the growth of the world's economy, it has also fueled the demand for medical supplies including herbal medicine [6]. Furthermore, it is estimated that only 5 to $10 \%$ of herbal medicines used by Malaysians is produced locally, the rest being imported, primarily from China, India, Indonesia and the United States [7]. Thus, it is unsurprising that the Malaysian government is heavily invested in the research and development of herbal products [4].

Highlighting the Malaysian government's commitment to expanding the herbal medicine industry, herbs is listed as the first Entry Point Project (EPP1) for the nation's Agriculture National Key Economic Areas [8]. A total of 18 high value herbal products has been listed under EPP1, one of them being Labisia pumila (Kacip Fatimah). L. pumila is highly-prized for its phenols, as research has found that it has numerous pharmacological properties; having anti-oxidant, anti-microbial, anti-inflammatory and anti-cancer potential [7].

Other parts of the plant, especially its leaves, is also used in traditional medicine. Although L. pumila has been used for centuries in Malaysia, it still holds an important part in Malaysian culture today. It is often taken on a regular basis, namely by Malay women [9]. This is due to modern perceptions that the plant is highly beneficial for the health of women. The herb is used to contract the uterus after childbirth, firm abdominal muscles, allay painful menstruation, treat irregular periods and to alleviate fatigue $[10,9,11,12]$. Moreover, the leaves and roots are used to regain strength after childbirth [9]. L. pumila as a traditional medicine is readily available in Malaysian market, sold in powders, extracts, pills, capsules and even in beverages such as tea and coffee [11]. However, the exact quality of these products available in the market remains questionable.

L. pumila can be found in shaded areas, growing on assorted soil types, such as humus-rich soils, sandy loam, deep clay soil or granite soils. $L$. pumila is usually abundant in understory, secondary forest, bamboo forest and peat forest [7]. Forest Research Institute Malaysia (FRIM) has taken the initiative to produce high quality planting materials of $L$. pumila through breeding and silviculture studies. The production of phenolic contents in plants and its general growth performance is influenced by various factors, including abiotic factors such as water, sunlight and soil. However, information on the effect of soil properties and soil amendments on the growth performance of L. pumila is still lacking [12]. Hence, this study was conducted to investigate the best combination of growing media for the cultivation of L. pumila. The effect of growing media on L. pumila production of secondary metabolite (total phenolic content) and general growth performance were studied for six months. The relationship between the different soil properties and the cultivation of $L$. pumila was also investigated. 


\section{Experimental Methods}

\subsection{Organic Compost and Growing Media}

This study used five different types of organic compost, that were prepared by grinding dried tree leaves with dried L. pumila leaves, using miller machine (Fig. 1). The grinded leaves were then mixed with SRF. Each of the compost had varying weight of $L$. pumila leaves, as shown in Table 1.

Table 1 Materials used for compost preparation

\begin{tabular}{ll}
\hline Compost Type & Composition \\
\hline Compost 1 & 5 kg dry tree leaves +500 g dry Kacip Fatimah + SRF \\
Compost 2 & 5 kg dry tree leaves +300 g dry Kacip Fatimah + SRF \\
Compost 3 & 5 kg dry tree leaves +200 g dry Kacip Fatimah + SRF \\
Compost 4 & 5 kg dry tree leaves + 100 g dry Kacip Fatimah + SRF \\
Compost 5 & 5 kg dry tree leaves + SRF \\
\hline
\end{tabular}

The composts were turn over every week with shovels to mix it up. SRF was added to the compost mixture every week, to keep the mixture moist and to assist in decomposition. When the compost temperature was constant, compost samples ( $20 \mathrm{~g}$ ) were collected from each compost type. The samples underwent nutrient analysis at the Soil Chemical Laboratory, FRIM. The $\mathrm{pH}$ was determined in distilled water and $\mathrm{KCl}\left(1 \mathrm{molL}^{-1}\right.$ solution) suspensions (1:2.5, weight/volume) using a combined glasscalomel electrode. Nitrogen, phosphorus and potassium was analyzed using the methods described by the United States Department of agriculture [13].

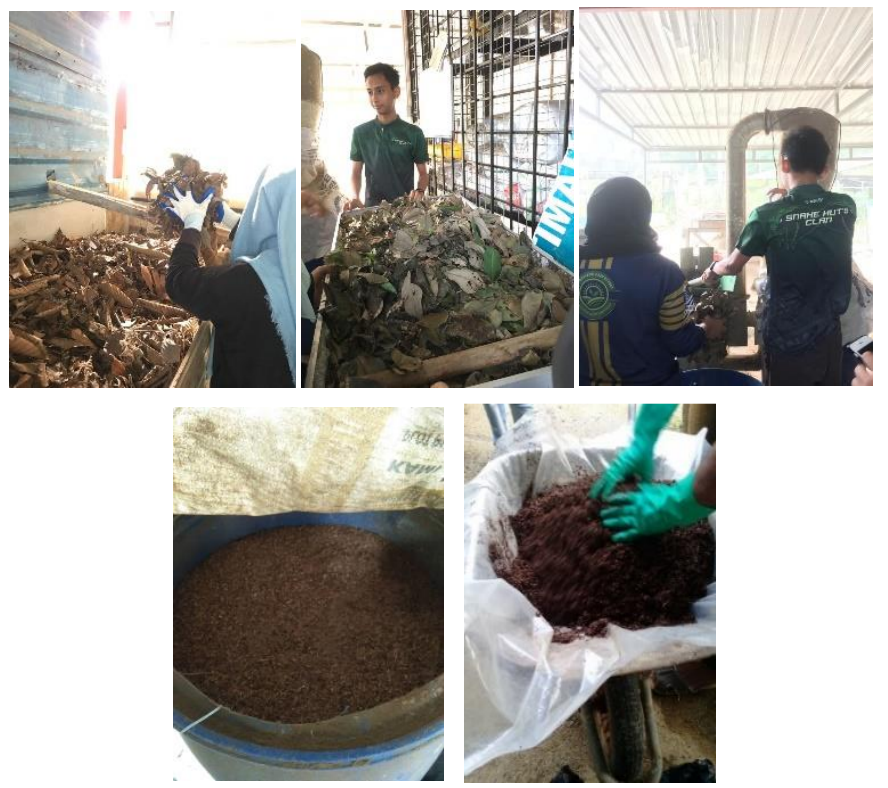

Fig. 1 Organic compost preparation Six combinations of growing media were prepared using the compost, including a control (Table 2)

Table 2 Growth media composition

\begin{tabular}{ll}
\hline Growing media & Composition ratio \\
\hline Control (C) & 2 top soil: 1 sand \\
Treatment 1 (T1) & 2 top soil: 1 compost $1: 1$ sand \\
Treatment 2 (T2) & 2 top soil: 1 compost $2: 1$ sand \\
Treatment 3 (T3) & 2 top soil: 1 compost $3: 1$ sand \\
Treatment 4 (T4) & 2 top soil: 1 compost $4: 1$ sand \\
Treatment 5 (T5) & top soil: 1 compost $5: 1$ sand \\
\hline
\end{tabular}

\subsection{Planting Materials}

A total of 180 uniform plantlets of L. pumila that were produced using tissue culture were selected as the planting materials for this study. The plantlets had undergone hardening process and were fit to be transferred into polybags. This ensured that all the planting materials were genetically identical, thus growth performance would solely be influenced by environmental factors. Each treatment was planted with 30 plantlets of $L$. pumila. The plantlets for all six treatments were arranged in a Complete Randomized Design (CRD). Growth parameters that were measured were plant height $(\mathrm{cm})$, leaf number, leaf length $(\mathrm{cm})$, leaf width $(\mathrm{cm})$ and collar diameter $(\mathrm{mm})$. The growth performance was compared between month 1 and month 6 of planting.

\subsection{Quantification of Total Phenolic Content}

A total of $20 \mathrm{~g}$ of L. pumila leaves were harvested from all six treatments after six months of planting. The leaves samples were cleaned under running tap water to remove any debris. The leaves were then cut into small pieces and soaked in $200 \mathrm{~mL}$ of $95 \%$ ethanol for 48 hours. Subsequently, the leaves' extract was filtered using sterilized Whatman No. 1 Filter Paper. The extracts were then subjected to rotary evaporator at $46{ }^{\circ} \mathrm{C}$ for 1 hour. The crude obtained was then weighed prior to total phenolic content (TPC) analysis. The TPC was determined using FollinCiocaltue reagent as described by Singleton and Rossi (1965) [14]. The sample was expressed in a gallic acid equivalents (GAE-TPC mg/g of crude extract) based on gallic acid standard curve.

\subsection{Statistical Analysis}

Statistical analysis for the plant growth performance and TPC was determined using a one-way analysis of variance (ANOVA) using Minitab Version 17. Fisher's least Significant Differences (LSD) was used for comparison of treatments mean where the $\mathrm{F}$ values were significant at $\mathrm{P} \leq 0.05$.

\section{Results and Discussion}

\subsection{General Properties of Organic Composts}

Table 3 shows the general properties of the five composts that were prepared. All the composts had a constant temperature of $27{ }^{\circ} \mathrm{C}$ after 56 days of composting. The percentage of nitrogen $(\mathrm{N})$ in all composts was almost similar, falling in the range of 1.25 to $1.34 \%$. This is slightly higher than the average nitrogen content of compost, which is $1.15 \%$ [15] However, plant available nitrogen almost exclusively consists of nitrate nitrogen, thus a high total nitrogen count doesn't necessarily mean high available nitrogen [16]. Depending on soil type and climatic conditions, available nitrogen in compost can be increased up to $15 \%$ [15]. Inadequate nitrogen will limit plant growth and reduce plant yield [16]. Thus, it is important to monitor available nitrogen levels throughout the cultivation process.

Similar to nitrogen, phosphorus (P) is vital for plant production. The concentration of phosphorus in all composts were similar, ranging from 0.10 to $0.12 \%$. This value is low, since the average concentration of phosphorus in compost is $0.62 \%$ to $0.85 \%$ [15]. Thus, there might be a need to increase $\mathrm{P}$ concentration by adding fertilizer.

Potassium $(\mathrm{K})$ concentration ranged from $0.62 \%$ to $0.7 \%$, the highest being in Compost 1 while the lowest being Compost 5 . Compost 1 had the highest amount of L. pumila leaves while Compost 5 had the lowest, thus it can be concluded that $L$. pumila leaves directly contributed to $\mathrm{K}$ concentrations in the compost. However, potassium concentration in all compost were lower than the average concentration in compost $(1.01 \%)$ [15]. As potassium is an essential nutrient that is second only to nitrogen, it is important that adequate soil amendments such as fertilizers, are added when using this compost.

The $\mathrm{pH}$ levels for all compost were acidic, ranging from 4.77 (Compost 5) to 5.26 (Compost 1). Like most tropical plants, L. pumila grows well on acidic soils, thus the $\mathrm{pH}$ levels of the composts might not be a limiting factor for the cultivation of $L$. pumila [11, 12]. However, even tropical plants cannot tolerate very acidic soils [17].

Table 3 Properties of organic compost after 56 days of decomposition

\begin{tabular}{llllll}
\hline Compost & $\mathrm{N}(\%)$ & $\mathrm{P}(\%)$ & $\mathrm{K}(\%)$ & $\mathrm{pH}$ & Temperature $(\circ \mathrm{C})$ \\
\hline 1 & 1.32 & 0.12 & 0.70 & 5.26 & 27 \\
2 & 1.34 & 0.11 & 0.66 & 5.18 & 27 \\
3 & 1.25 & 0.10 & 0.65 & 5.06 & 27 \\
4 & 1.31 & 0.11 & 0.63 & 4.89 & 27 \\
5 & 1.32 & 0.12 & 0.62 & 4.77 & 27 \\
\hline
\end{tabular}

\subsection{Plant Height of Labisia pumila}

As shown in Fig. 2, plant height of L. pumila was significantly affected $(\mathrm{P} \leq 0.05)$ by growing media, one month after planting. The highest mean of plant height was observed in T1 $(4.14 \mathrm{~cm})$, followed by T2 $(4.00 \mathrm{~cm})$ and T5 $(3.88 \mathrm{~cm})$. T3 recorded $3.64 \mathrm{~cm}$ of plant height which is higher than control $(2.89 \mathrm{~cm})$, whereas the lowest value was observed in T4 $(2.61 \mathrm{~cm})$. The results may have varied because the plants were still at their vegetative stage, when the demand for nitrogen is critical for stalks and foliage development. However, after six months, all the plants showed good increment (about 2.0 to $6.0 \mathrm{~cm}$ ), and had no significant differences between them, with the exception of control, which was significantly lower than all other treatments. The highest plant height is recorded by T2 $(9.25$ 
$\mathrm{cm})$, followed by T5 $(8.55 \mathrm{~cm}), \mathrm{T} 4(8.26 \mathrm{~cm}), \mathrm{T} 2(8.22 \mathrm{~cm})$ and T3 $(7.20$ $\mathrm{cm})$. Hence, all treatments were able to supply sufficient nutrients for plant growth, with the exception of control.

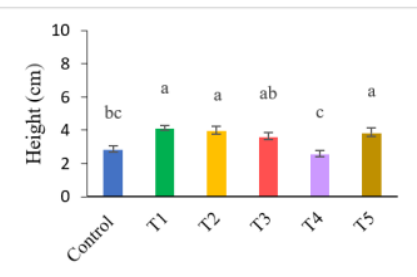

Treatment (Soil Media)

After 1 month

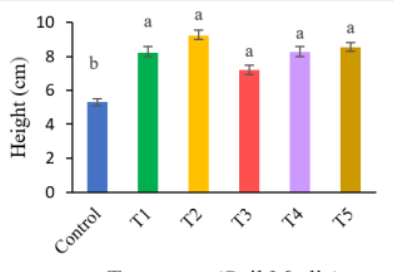

Treatment (Soil Media)

After 6 months
Fig. 2 Plant height of Labisia pumila (one and six months after planting)

\subsection{Leaf Number of Labisia pumila}

There was no significant difference in the number of leaves after one month of planting (Fig. 3). The mean number of leaves for all treatments were between 3.91 to 5.11, while the mean number of leaves for control was 4.05. After six months, the number of leaves increased about one to four leaves. T4 and T5 had the highest number of leaves (8) followed by T3 (7), T2 (7) and T1 (6). Similar to plant height, control had the lowest number of leaves $(5)$.

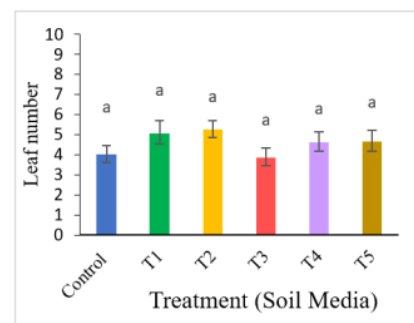

After 1 month

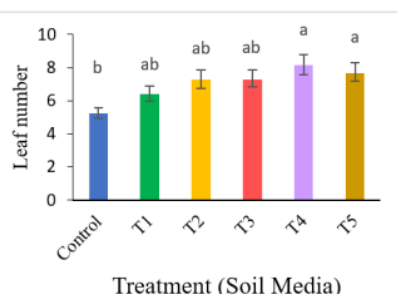

After 6 months
Fig. 3 Number of leaves of Labisia pumila (one and six months after planting)

\subsection{Leaf Length of Labisia pumila}

In term of leaf length, there were no significant differences among all treatments (Fig. 4). Only control was significantly lower after six months. The highest value of leaf length, one month after planting was T4 (4.22 $\mathrm{cm})$, however it was not significantly different at $\mathrm{p} \leq 0.05$.

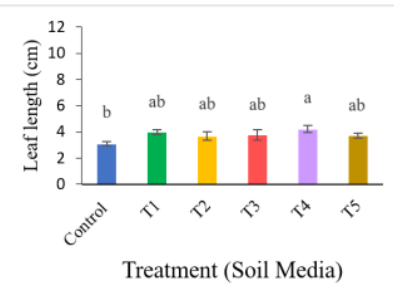

After 1 month

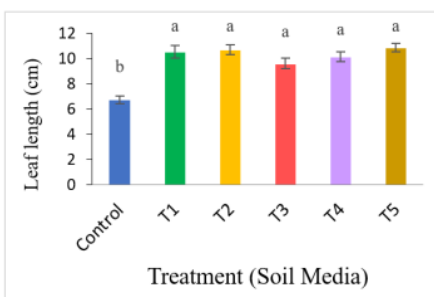

After 6 months
Fig. 4 Leaf length of Labisia pumila (one and six months after planting)

\subsection{Leaf Width of Labisia pumila}

As shown in Fig. 5, T3 had the significantly highest value of leaf width $(3.05 \mathrm{~cm})$ after one month. After six months, T3 had the second lowest leaf width $(4.59 \mathrm{~cm})$; The lowest being control, which was significantly lower than all other treatments. Meanwhile, T2 had the highest leaf width (5.38 $\mathrm{cm})$ followed by T5 $(5.25 \mathrm{~cm}), \mathrm{T} 1(5.07 \mathrm{~cm})$ and T4 $(4.88 \mathrm{~cm})$, but were not significantly different from one another.
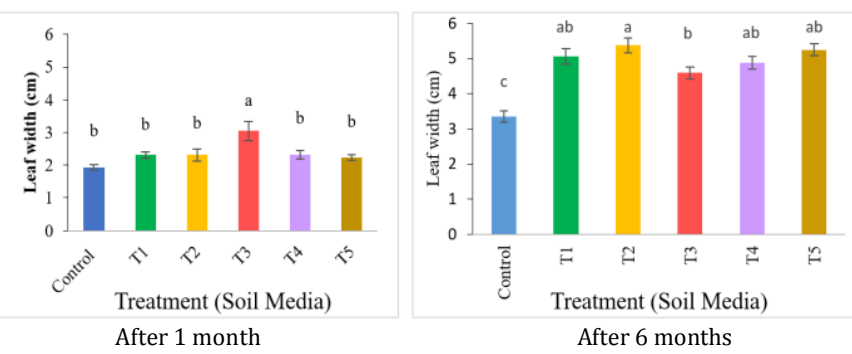

Fig. 5 Leaf width of Labisia pumila (one and six months after planting) https://doi.org/10.30799/jnpr.091.20060201

\subsection{Collar Diameter of Labisia pumila}

Fig. 6 shows that T3 had the highest value on collar diameter $(2.50 \mathrm{~mm})$, one month after planting. The mean value of collar diameter for T2 (1.99 $\mathrm{mm}), \mathrm{T} 4(2.02 \mathrm{~mm}), \mathrm{T} 5(2.07 \mathrm{~mm})$ and control $(1.83 \mathrm{~mm})$ were not significantly different after the first month. As expected, the collar diameter for all five treatments increased six months after planting. All treatments had no significant difference in collar diameter, with the exception of control that had significantly lower readings. All growth parameters showed that all treatments (with the exception of control) could supply sufficient nutrient for the growth of L. pumila. This is most likely due to sufficient NPK in all growth mediums, supplied by their respective composts [15]. Therefore, there isn't a need for other soil amendments, such as fertilizers.
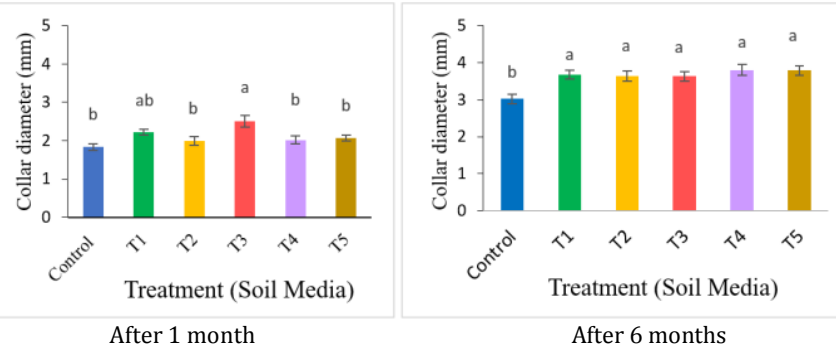

Fig. 6 Collar diameter of Labisia pumila(one and six months after planting)

\subsection{Total Phenolic Content of Labisia pumila}

Total phenolic content (TPC) was analysed six months after planting, as the leaves at this stage would have fully developed. As shown in Fig. 7, T1 had significantly higher concentration of TPC (80.6 mg GAE/g), followed by $\mathrm{T} 4$ (72.4 g GAE/g). Whereas, the TPC values were not significant different between T2, T3, T5 and the control. The range of TPC value for all treatments was between $57.0 \mathrm{mg} \mathrm{GAE} / \mathrm{g}$ to $59.5 \mathrm{mg}$ GAE/g. Studies have found that the application of organic composts can enhance antioxidant activities of certain plants, increasing their TPC levels [15]. Ibrahim et al. stated that TPC of $L$. pumila is directly affected by soil nitrogen content [12]. Thus, it is possible that T1 recording the highest TPC content is due to the high nitrogen concentration in Compost 1. Besides nitrogen, studies have found that potassium too affected TPC [18], thus Compost 1 having the highest concentration of potassium $(0.7 \%)$ could've contributed to the increased TPC in L. pumila. Another expect that needs to be taken into consideration is that Compost 1 had the highest $\mathrm{pH}$ levels (5.26), thus soil $\mathrm{pH}$ could also be a contributing factor in TPC concentrations. Most tropical plants, including L. pumila, is able to thrive under acidic conditions, but highly acidic soils can still limit the growth performance of some tropical species [17]. Moreover, soil pH affects soil nutrient availability, especially micronutrients; Which can affect TPC content [12]. Thus, for the cultivation of L. pumila, soil $\mathrm{pH}$ levels need to be continuously monitored to ensure optimal TPC.

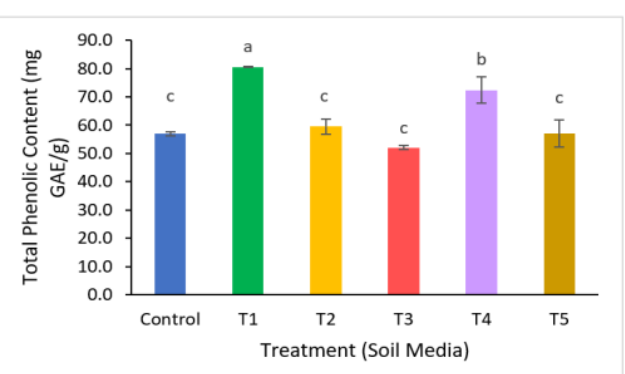

Fig. 7 Total phenolic content in Labisia pumila leaves after six months of planting

The growth parameters showed that all treatments (with the exception of control), could supply sufficient nutrients for optimal L. pumila growth. However, TPC wasn't consistent among the treatments. As TPC can be affected by environmental conditions, including soil properties, it can be concluded that Treatment 1 , that contained Compost 1, provided the best condition for increased TPC in L. pumila. Long-term observation is required to truly assess the effectiveness of Compost 1 in achieving optimal growth for L. pumila.

\section{Conclusion}

In conclusion, growing media with the combination of compost significantly gave good response to the growth of L. pumila. Whereas for 
TPC analysis, plants grown in Treatment 1 (T1) produced the highest amount of TPC and the addition of Kacip Fatimah leaves (500 g) probably influence the TPC production which require further study.

\section{Acknowledgements}

The authors would like to express their gratitude for receiving the Rancangan Malaysia ke-11 grant which provided the necessary funding to undertake this research.

\section{References}

[1] M. Abdullah, M.P. Mamat, M.R. Yaacob, A. Radam, H.F. Lim, Estimate the conservation value of biodiversity in national heritage site: A case of Forest Research Institute Malaysia, Proc. Environ. Sci. 30 (2015) 180-185.

[2] J. Kaur, N. Hamajima, E. Yamamoto, Y.M. Saw, T. Kairya, et al., Patient satisfaction on the utilization of traditional and complementary medicine services at public hospitals in Malaysia, Compl. Ther. Med. 42 (2019) 422-428.

[3] World Health Organization (WHO), Global report on traditional and complementary medicine 2019, World Health Organization, Geneva, 2019.

[4] T.T.Y. Chin, J.L. Chelyn, N.A.M. Yusof, T.B. Ping, A. Fazlin, et al., Malaysian herbal monograph development and challenges, J. Herb. Med. 23 (2020) 100380:1-6.

[5] I.H. Burkill, $A$ Dictionary of the Economic Products of the Malay Peninsula, $2^{\text {nd }}$ Ed., The Ministry of Agriculture and Cooperatives, Kuala Lumpur, 1966.

[6] B. Vellingiri, K. Jayaramayya, M. Iyer, V. Narayanasamy, V. Govindasamy, et al., COVID-19: a promising cure for the global panic, Sci. Total Environ. 725 (2020) 138277:1-18

[7] S. Foster, Balancing nature and wellness --Malaysian traditions of "Ramuan" -
The history, culture, biodiversity and scientific assimilation of medicinal plants in Malaysia, HerbalGram, J. Am. Bot. 84 (2009) 30-43.

[8] F. Ahmad, M.A. Shah Zaidi, N. Sulaiman, F.A. Abdul Majid, Issues and challenges in the development of the herbal industry in Malaysia, In: Proceedings IPERKEM, Universiti Kebangsaan Malaysia, Malaysia,, 2015, pp.227-238.

[9] W.E. Hassan, M. Mustaffa, Healing herbs of Malaysia, Federal Land Development Authority, Kuala Lumpur, 2008.

[10] M. Zakaria, M.A. Mohd, Traditional Malay medicinal plants, Penerbit Fajar Bakti, Sdn. Bhd, Kuala Lumpur, 1994.

[11] M. Norhaiza, M. Maziah, M. Hakiman, Antioxidative properties of leaf extracts of a popular Malaysian herb, Labisia pumila, J. Med. Plants Res. 3(4) (2009) 217-223.

[12] M.H. Ibrahim, H.Z. Jaafar, E. Karimi, A. Ghasemzadeh, Impact of organic and inorganic fertilizers application on the phytochemical and antioxidant activity of Kacip Fatimah (Labisia pumila Benth), Molecules 18(9) (2013) 1097310988.

[13] USDA, Soil Survey Field and Laboratory Methods Manual, 2nd Ed., United States Department of Agriculture (USDA), USA, 2014.

[14] V.L. Singeleton, J.A. Rossi, Calorimetry of total phenolic with phosphomolybdic phosphotungstic acid reagents, Am. J. Enol. Viticult. 16 (1965) 144-158.

[15] K. Fricke, H. Vogtmann, Compost quality: Physical characteristics, nutrient content, heavy metals and organic chemicals, Toxicol. Environ. Chem. 43 (1994) 95-114.

[16] S.J. Leghari, N.A. Wahocho, G.M. Laghari, L.A. Hafeez, B.G. Mustafa, T.K. Hussain, et al., Role of nitrogen for plant growth and development: A Review, Adv. Environ. Biol. 10(9) (2016) 209-218.

[17] B.X. Pinho, M. Tabarelli, M.M.J. Engelbrecht, J. Sfair, F.P.L. Melo, Plant functional assembly is mediated by rainfall and soil conditions in a seasonally dry tropical forest, Basic Appl. Ecol. 40 (2019) 1-11.

[18] S. Sharafzadeh, Effect of nitrogen, phosphorous and potassium on growth, essential oil and total phenolic content of garden thyme (Thymus vulgaris L.) Adv. Environ. Biol. 5(4) (2011) 150-162. 